\title{
The structure of mixed-species bird flocks, and their response to anthropogenic disturbance, with special reference to East Asia
}

\author{
Eben Goodale ${ }^{1}$, Ping Ding ${ }^{2}$, Xiaohu Liu ${ }^{3}$, Ari Martínez ${ }^{4}$, Xingfeng $\mathrm{Si}^{2}$, Mitch Walters ${ }^{5}$ and Scott K. Robinson ${ }^{6^{*}}$
}

\begin{abstract}
Mixed-species flocks of birds are distributed world-wide and can be especially dominant in temperate forests during the non-breeding season and in tropical rainforests year-round. We review from a community ecology perspective what is known about the structure and organization of flocks, emphasizing that flocking species tend to be those particularly vulnerable to predation, and flocks tend to be led by species that are able to act as sources of information about predators for other species. Studies on how flocks respond to fragmentation and land-use intensification continue to accumulate, but the question of whether the flock phenomenon makes species more vulnerable to anthropogenic change remains unclear. We review the literature on flocks in East Asia and demonstrate there is a good foundation of knowledge on which to build. We then outline potentially fruitful future directions, focusing on studies that can investigate how dependent species are on each other in flocks, and how such interdependencies might affect avian habitat selection in the different types of human-modified environments of this region.
\end{abstract}

Keywords: Biodiversity crisis, Biological networks, Community assembly, Competition, Interspecific communication, Keystone species, Mutualism, Predation

\section{Introduction}

Mixed-species flocking of birds (hereafter referred to as "flocking") is a well-studied, broadly distributed biological phenomenon. It occurs in many different kinds of ecosystems, including pelagic, wetland, and grassland systems, and in many different groups of birds including waterfowl, wading birds, and granivores (see review of Harrison and Whitehouse 2011). Most research, however, has concentrated on flocks in forested systems, for which there are flock descriptions from all continents other than Antarctica (Fig. 1; see review by Powell 1985; and meta-analysis by Sridhar et al. 2009), and such forest flocks will be the focus of this review. Mixed-species flocks must be distinguished from assemblages that gather at a localized resource in that they are always moving (Powell 1985), and most species involved in forest flocks

\footnotetext{
* Correspondence: srobinson@flmnh.ufl.edu

${ }^{6}$ Florida Museum of Natural History, University of Florida, Gainesville, FL 32611, USA

Full list of author information is available at the end of the article
}

are insectivorous, with some exceptions (Munn 1985; Powell 1985). In some habitats, such as temperate forests in winter and lowland tropical forests, mixed-species flocks dominate entire bird communities (for example, in some areas more than half of all birds are found within them; Eguchi et al. 1993; Latta and Wunderle 1996; Goodale et al. 2009).

Given this broad distribution and dominance of mixed-species flocks in some areas, any study of bird community organization must incorporate them in some way. Mixed-species flocks qualify as "community modules" (sensu Holt 1997) in which biotic interactions such as competition, mutualisms, and predation are highly concentrated in space and time and, therefore, are especially amenable to scientific investigation, and naturally interesting to community ecologists. One approach derived from community ecology is to analyze flocks as a subset of the avifauna, and to try to understand and predict which species should be in flocks and what roles different species play (Goodale et al. 2010). A second and 


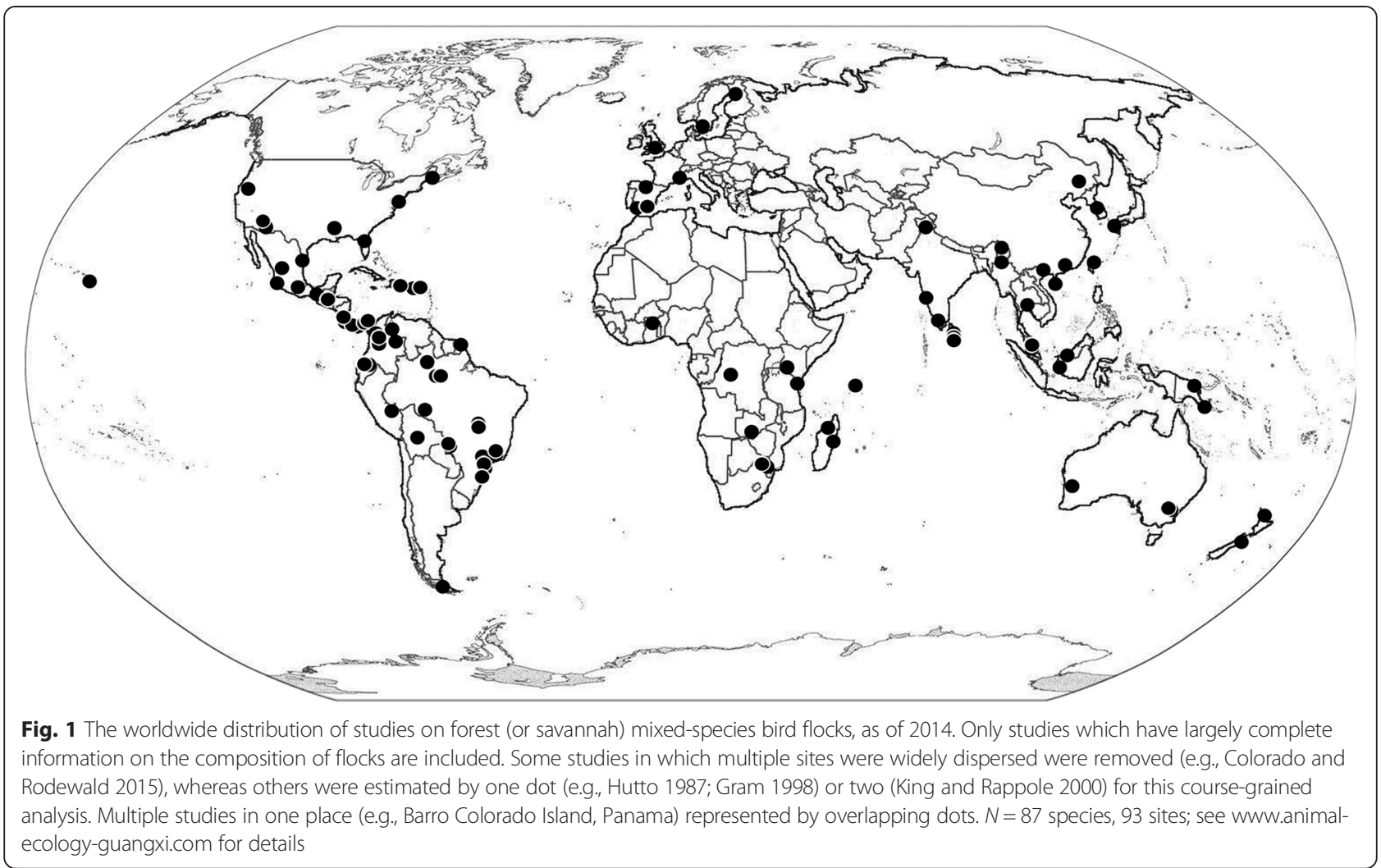

perhaps more difficult approach is to ask how flocks affect the overall bird community. A recent review (Harrison and Whitehouse 2011) argued that, in an evolutionary sense, the behavior of some species in mixed-species flocks has created unique ecological niches for other species. But the role of species in creating niches for others is also relevant in ecological time, to understand the importance of flocking to conservation. If the presence of flocks alters the fitness and distribution of the species that participate in them (e.g., Jullien and Clobert 2000), then any factors that cause flocks to break down could alter the entire composition of communities. This issue is of special concern given the mounting evidence that a wide array of anthropogenic threats negatively affects flocks (Van Houtan et al. 2006; Mokross et al. 2014; see also section below on this topic). Potentially, the loss of a few crucial members of mixed-species flocks as a result of anthropogenic habitat alteration (e.g., habitat fragmentation, silviculture) could reduce the fitness of many other species.

The purpose of this review is to examine the ecological organization of mixed-species flocks, to understand how the structure of these communities might influence their response to human disturbance, and then to outline future directions of research on these issues, especially in East Asia, where human disturbance is pervasive. The review is organized as follows. In the first section, we describe what is known about flock community assembly: what determines which species do and do not join flocks and what are the characteristics of species that lead flocks. In the second section, we review how human habitat modification affects flock structure, and discuss whether participating in flocks causes organisms to be particularly vulnerable or resistant to such disturbance. In the third section, we review studies of flocks in East Asia, which have not before been summarized, and ask what foundation we have to build upon. In the fourth section, we propose some lines of research that fill the gaps in knowledge identified in the previous sections. We suggest that East Asia presents unique opportunities to understand the level of interdependence of the species that participate in flocks and the implications of mixedspecies flocking for conservation.

While the benefits of mixed-species flocking to birds is not the focus of this review, it remains an important backdrop to the issues we discuss, and hence a quick review is necessary. There are two main hypotheses underlying the benefits of flocks: improved foraging efficiency and increased predator avoidance (Morse 1977; Sridhar et al. 2009). These two hypotheses apply to both monospecific and multi-species flocks and are not mutually exclusive; indeed, they interact because reduced individual investment in vigilance can lead to increased investment in foraging (Caraco et al. 1980; Sullivan 1984; Sridhar et al. 2009). Although there is strong evidence 
that conspecific groupings allow animals to find food through social information sharing (Galef and Giraldeau 2001; Aplin et al. 2012), the evidence that birds learn about food from heterospecifics in flocks is limited (Krebs 1973; Waite and Grubb 1988), with the exception of a class of sallying birds that catch insects disturbed by other species or even kleptoparasitize them (Hino 1998; Satischandra et al. 2007; Sridhar and Shanker 2014). In contrast, the evidence that birds reduce their predation risk in flocks through a variety of mechanisms is strong and continues to accumulate (Thiollay and Jullien 1998; Thiollay 1999a; Sridhar et al. 2009). The reader is referred for further reading to a series of reviews over several decades: Morse (1977), Diamond (1981), Powell (1985), Greenberg (2000), and Colorado (2013).

\section{Review}

\section{A. The structure of mixed-species flock communities Explaining patterns in flock participation}

Perhaps the most basic question about flocks is why are some species found in flocks and some not. As explained above, many flocking species tend to be insectivorous because that diet is most amenable to the constant movement of a flock, compared to other diets such as frugivory that require active searching for a clumped resource. Beyond diet, predation-related ecology, competition and use of space may influence species' participation in flocks, and we address these issues here in turn.

Vulnerability to predation appears to be the best predictor of high flock propensity (that is, a high percentage of individuals in flocks; Buskirk 1976; Thiollay and Jullien 1998; Thiollay 1999a, 2003). Species with high propensity to flock either have a foraging technique or a microhabitat that makes them more exposed to predators (Thiollay 2003). Further, flocking behavior is more intense where predation pressure is higher (Thiollay 1999b). These hypotheses, which were derived from studies at both a regional (Thiollay and Jullien 1998; Thiollay 2003) and global (Thiollay 1999a) level, makes it possible to predict with reasonable accuracy which species will and will not be in flocks. At the same time, it should be realized that this body of literature did not incorporate phylogenetic relatedness into their analyses. Members of some families or genera tend to be usually found in flocks, and it is yet unclear whether evolutionary history, in addition to, or instead of, predation-related or foraging-related ecology, explains the presence of these birds in mixed-species flocks (Gómez et al. 2010).

Does competition also influence which species participate in flocks? Graves and Gotelli (1993) asked this question for data from Munn and colleagues' studies (Munn 1985; see also Pierpont 1986). They found that some close congeners exhibited a 'checkerboard' pattern in which one species was present when the other was absent. However, a re-analysis of this data that looked at all congeneric pairs did not find a significant trend for congeners to avoid each other in Munn's data, and quite to the contrary, found evidence at the global scale that congeners were more likely to associate together than expected by chance (Sridhar et al. 2012). More generally, this meta-analysis found that a considerable proportion of studies indicated that species tend to associate in flocks with other species that share their body size and/or foraging behavior (Sridhar et al. 2012; but see Colorado and Rodewald 2015 for a regional study that does not show this pattern).

While competition may not usually restrict species from joining flocks, some species have been shown to change their foraging ecology or spatial position in flocks in a manner suggesting they are avoiding competition. Many studies, especially on tit-led temperate systems, have shown that tits may change where they feed in trees (Morse 1970; Alatalo 1981; Alatalo et al. 1985, 1987; Krams 2001; Jabłoński and Lee 2002) or their foraging technique (Pomara et al. 2003) to avoid dominant species in flocks. At the same time, however, other studies have demonstrated that species might actually move their foraging location to be close to other species, particularly leaders (Latta and Wunderle 1996; Hino 1998; Hsieh and Chen 2011; Farine and Milburn 2013), and sallying species adjust their location to capture insects disturbed by gleaners (Satischandra et al. 2007; Srinivasan and Quader 2012; Sridhar and Shanker 2014). Valburg (1992) described a primarily frugivorous species that was insectivorous in flocks. In summary then, studies to date suggest that facilitation (through reduced risk of predation or increased foraging efficiency) is as important as competition in determining spatially where in flocks species are present relative to other species, and is more important than competition in determining which species are present in flocks (Sridhar et al. 2012).

The participation of species in flocks can also be influenced by how different species use space. For example, in color-banded studies it has been shown that species with small territories drop out of flocks when they leave their territories, whereas species with very large territories may even move between different flocks (Munn and Terborgh 1979; Gradwohl and Greenberg 1980). Hence species with larger territories may be more consistently with flocks (Pomara et al. 2007). Unfortunately, our knowledge of this issue is limited by the very small number of studies on mixed-species flocks that have color-banded individuals, limited to Central America (Buskirk et al. 1972; Gradwohl and Greenberg 1980), Amazonian Peru and French Guinea (Munn and Terborgh 1979; Munn 1985; Jullien and Thiollay 1998), and Australia (Farine and Milburn 2013).

\section{Explaining patterns in flock organization and leadership}

A second important question about flocking is which species play important roles in flock organization. 
Winterbottom (1943) and Moynihan (1962) were the first to identify "nuclear" species, which were hypothesized to stimulate the formation and cohesion of mixed-species flocks, and "associate" species that follow the nuclear species. Nuclear species can be identified by investigating which species lead flocks (Develey and Stouffer 2001; Goodale and Beauchamp 2010; Contreras and Sieving 2011), or their centrality in network analyses (Sridhar et al. 2013), or many species being positively associated with them (Srinivasan et al. 2010).

Nuclear species have several characteristic properties. Most obviously, they are often intraspecifically gregarious (Goodale and Beauchamp 2010); indeed many are cooperative breeders (Sridhar et al. 2009). This gregariousness makes them conspicuous in flocks, and the possibly kin-selected signals they use for intraspecific communication, especially those related to predation threats, can be eavesdropped on by other species (Goodale et al. 2010; Harrison and Whitehouse 2011). Nuclear species also tend to be generalists that range over a wide variety of foraging heights, and leaf-gleaning species that disturb insects as they move, making them attractive to follow for a wide-range of other species (Hino 1998; Hsieh and Chen 2011).

A separate class of species, known as "sentinel" species, may also be important to flocks because they provide information about predators, because they are sallying (fly-catching) species that frequently scan for insects (Greig-Smith 1981; Munn 1984; Terborgh 1990; Goodale and Kotagama 2005a). Such species may meet Moynihan's (1962) criterion of being important for the cohesion or formation of flocks, although they are rarely gregarious, and they do not necessarily lead flocks (Goodale and Kotagama 2005a).

Species that are laggards in flocks may be those whose foraging speed is not completely compatible with the flock's; such incompatibilities may represent a cost of flocking for some species (Hutto 1988; Darrah and Smith 2013). For example, species that spend a long time foraging in one place, such as woodpeckers and parakeets, are the last species to cross open areas in Sri Lankan flocks, as they appear to need to fly long distances to catch up to the flock (Kotagama and Goodale 2004). Incompatibilities between the rate of movements of leading species and potential followers may explain why some intraspecifically gregarious species do not attract followers when foraging (Greenberg 2000; Chen and Hsieh 2002; Zhang et al. 2013).

\section{The dependence of species on flocks and nuclear species}

While many benefits to mixed-species flocking have now been suggested, the actual fitness benefits of participating in flocks have rarely been measured. In a metaanalysis, Jullien and Clobert (2000) showed that obligate flock species (those that forage exclusively in flocks) have higher survival rates than solitary or pair-feeding species. Dolby and Grubb (1998) found that an attendant species had poorer body condition following the removal of a flock leader. Nevertheless, there is a clear need for further studies of the extent to which species depend upon flocks for their fitness.

\section{B. The response of flocks to anthropogenic disturbance Why study the responses of flocks to disturbance?}

There are three main reasons that have been proposed for focusing on mixed-species flocks when studying how communities respond to habitat alteration, as compared to the whole bird community. First, flocks are particularly easy to locate and observe and can serve as a surrogate for the whole community (Lee et al. 2005). Second, conservation strategists are increasingly calling for the protection of species interactions and aspects of community structure, above and beyond the protection of species themselves (Tylianakis et al. 2009; Kiers et al. 2010; Valiente-Banuet et al. 2015), and flocks are an important type of mutualism. Third, flocking birds may be especially vulnerable to disturbance, and the loss of flocks could have ramifications for the overall bird community. Indeed, important early work on avian responses to habitat alteration in Amazonia showed flocking species were particularly affected (Thiollay 1992; Stouffer and Bierregaard 1995). In the accumulating body of literature about how flocks respond to anthropogenic disturbance, most papers simply document how flock qualities change along the disturbance gradient, but a few also tackle the question of why flock species might be expected to be particularly sensitive.

\section{Empirical studies of how flocks respond to anthropogenic disturbance}

Two main aspects of anthropogenic disturbance have been studied primarily in flock studies so far. The first is fragmentation (Stouffer and Bierregaard 1995; Fernández-Juricic 2000, 2002; Maldonado-Coelho and Marini 2000, 2004; Tellería et al. 2001; Van Houtan et al. 2006; Sridhar and Sankar 2008; Cordeiro et al. 2014; Mokross et al. 2014). The general result of this literature is that flock qualities (size in individuals, species richness, encounter rate and even network characteristics; see Mokross et al. 2014 about networks) decrease as fragmentation increases, with fragments below 10 ha being especially effected (Maldonado-Coelho and Marini 2004; Mokross et al. 2014). The second gradient is land-use intensity, including the effects of selective logging (Thiollay 1992, 1999b), various kinds of agriculture or agroforestry (Sidhu et al. 2010; Zhang et al. 2013; Goodale et al. 2014; McDermott and Rodewald 2014; Colorado and Rodewald, in press), livestock grazing and firewood/ 
charcoal collection (Knowlton and Graham 2011), and urbanization (Lee et al. 2005). Again, flock structure decreases as intensity of land degradation increases, most likely due to changes in the structural complexity of different habitats (Lee et al. 2005; Zhang et al. 2013; Colorado and Rodewald, in press), or the percentage of forest cover near the site at a landscape level (Colorado and Rodewald, in press).

In addition to these two major types of gradients, Develey and Stouffer (2001) have found that roads can stop the movement of mixed-species flocks, and Tubelis et al. (2006) and Péron and Crochet (2009) have studied how flocks change at a forest-savannah edge, suggesting that flocks may help forest-interior species move closer to non-forest habitats (see below).

\section{Are flocking species especially sensitive or resistant to human disturbance?}

In studying how flocks respond to anthropogenic disturbance, several studies have tried to distinguish between how disturbance affects flocks and how it affects the pool of birds at an area available to flock, by taking into account data on the overall abundance of birds in the community (Fernández-Juricic 2002; Sridhar and Sankar 2008; Sidhu et al. 2010; Goodale et al. 2014). While Fernández-Juricic (2002) found that the total bird density in fragments was a good predictor of the probability of encountering flocks, the other studies found that flocking propensity decreased in highly modified environments (very small fragments in Sridhar and Sankar 2008; and areas of intense agriculture for the studies of Sidhu et al. 2010; Goodale et al. 2014). In these highly disturbed areas, flocks often do not persist and flocking species are more affected than other species. That mixedspecies flocks breakdown in non-forested habitats is perhaps not surprising given that they are considered to be an adaptation to the vertical structural complexity provided by forest habitat (Terborgh 1990). Indeed, the driving force behind flock breakdown in non-forested environments may be the lack of complex vegetation (Lee et al. 2005).

Another potential mechanism that may cause flocking species to be more vulnerable to human disturbance and specifically fragmentation is their use of space. Van Houtan et al. (2006) worked in Amazonia with a system where flocks maintain multi-species territoriality.

(Munn and Terborgh 1979; Jullien and Thiollay 1998; Martínez and Gomez 2013), and found that the species that have higher flocking propensity in undisturbed habitat, and species that remain in flocks in disturbed habitat (as opposed to dropping out), are more likely to go extinct in fragmented areas. However, it is not clear that this mechanism operates in other areas, where flocks seem more like "waves" (McClure 1967), with birds joining and leaving at their own territory borders.
In contrast to the ideas above, it is also possible that flocking may benefit species in degraded landscapes because they help species adapt to hostile environments (Morse 1970) and forest-preferring birds might rely more on flocks when outside of forests. For example, experimental evidence has shown that forest birds are more likely to go into an open area in the presence of a nuclear flocking species (Dolby and Grubb 2000; Sieving et al. 2004). The edge studies discussed above suggest that flocking can encourage species to persist in open and hence risky areas: birds in mixed-species flocks traveled farther from forest than those that did not participate (Tubelis et al. 2006; Péron and Crochet 2009). Even where flocks do not persist at high densities in human disturbed environments, those flocks that do remain could be important refuges for forest-preferring species.

A final possible effect of flocks on participating species' vulnerability to anthropogenic habitat alteration could also be a result of species interactions and dependencies in flocks. If a species $\mathrm{A}$ is important to flocks, and a species $\mathrm{B}$ joins flocks to follow or derive benefits from $A$, then the habitat choices of A could alter the habitat preferences of B, a "within trophic cascade" analogous to trophic cascades in which top carnivores have large effects on communities (e.g., Terborgh et al. 2001). Several studies have implicated the absence of nuclear species as a strong contributor to the breakdown of flock structure (Maldonado-Coelho and Marini 2004; Sridhar and Sankar 2008; Zhang et al. 2013; Cordeiro et al. 2014). New analysis of Goodale and colleagues' data of flocks in Sri Lanka (Goodale et al. 2014) shows that at intermediate elevations, two different flock leaders, a babbler and a white-eye, vary in their sensitivity to land-use intensity, with babblers being more confined to forest (Mammides et al., unpublished manuscript). Other species show distinct preferences for one leader over the other, related to their body size, and this may affect their habitat selection; for example, several large threatened species are found mostly in babbler flocks and this may underlie their exclusivity to forest. Although a nuclear species, like this babbler in Sri Lanka, may be fairly common, it could be considered as a target of conservation if endangered species are dependent on it.

\section{The structure and composition of flocks in East Asian forests}

We next consider what foundation of knowledge we have on flocks in the East Asian region. In Table 1, we summarize the major studies of forest mixed-species flocks for the region, organized by latitude. Our search for literature included articles in Chinese, and reference books on Chinese birds (e.g., Zhuge 1990; Zhao 2001); unfortunately, we were not able to do a similar search in 
Table 1 Major flock studies in East Asia, with data on their species richness and leadership

\begin{tabular}{|c|c|c|c|c|c|c|c|c|}
\hline \multirow[t]{2}{*}{ Authors (year of publication) } & \multirow{2}{*}{$\begin{array}{l}\text { Province or } \\
\text { Island }\end{array}$} & \multirow[t]{2}{*}{ Latitude } & \multirow[t]{2}{*}{ Longitude } & \multirow[t]{2}{*}{ Habitat } & \multicolumn{3}{|c|}{ Species richness } & \multirow[t]{2}{*}{ Leadership } \\
\hline & & & & & $>25 \%$ & $>10 \%$ & $>5 \%$ & \\
\hline Zou et al. (2011) & Hainan & $18^{\circ} 23^{\prime}-18^{\circ} 52^{\prime} \mathrm{N}$ & $108^{\circ} 36^{\prime}-109^{\circ} 05^{\prime} \mathrm{E}$ & Mature & 4 & 11 & 21 & Alcippe hueti \\
\hline Jiang (2007) & Guangxi & $\sim 22^{\circ} 28^{\prime} \mathrm{N}$ & $\sim 106^{\circ} 57^{\prime} \mathrm{E}$ & $\begin{array}{l}\text { Successional } \\
\text { and mature }\end{array}$ & 6 & 16 & 25 & Alcippe davidi \\
\hline Zhang et al. (2013) & Guangdong & $23^{\circ} 09^{\prime}-23^{\circ} 11^{\prime} \mathrm{N}$ & $112^{\circ} 30^{\prime}-112^{\circ} 33^{\prime} E$ & Mature & 6 & 12 & 17 & Alcippe hueti \\
\hline Zhang et al. (2013) & Guangdong & $23^{\circ} 09^{\prime}-23^{\circ} 11^{\prime} \mathrm{N}$ & $112^{\circ} 30^{\prime}-112^{\circ} 33^{\prime} E$ & Successional & 3 & 8 & 11 & $\begin{array}{l}\text { Zosterops japonicus } \\
\text { (but not "cohesive") }\end{array}$ \\
\hline $\begin{array}{l}\text { Chen and Hsieh (2002); } \\
\text { Hsieh and Chen (2011) }\end{array}$ & Taiwan & $\sim 24^{\circ} 34^{\prime} \mathrm{N}$ & $\sim 121^{\circ} 34^{\prime} \mathrm{E}$ & Mature & 8 & 12 & 16 & Alcippe morrisonia \\
\hline Seki and Sato (2002) & Kyushu & $\sim 32^{\circ} 49^{\prime} \mathrm{N}$ & $\sim 130^{\circ} 44^{\prime} \mathrm{E}$ & Mature & $\mathrm{n} / \mathrm{a}$ & $\mathrm{n} / \mathrm{a}$ & $\mathrm{n} / \mathrm{a}$ & $\begin{array}{l}\text { Aegithalos caudatus; } \\
2 \text { tits also dominant }\end{array}$ \\
\hline Suzuki (2012) & Honshu & $36^{\circ} 21^{\prime}-36^{\circ} 22^{\prime} \mathrm{N}$ & $138^{\circ} 35^{\prime}-138^{\circ} 36^{\prime} E$ & Mature & $<4$ & $<4$ & $<4$ & Dominated by 3 tit species \\
\hline $\begin{array}{l}\text { Kubota and Nakamura (2000); } \\
\text { Nakamura and Shindo (2001) }\end{array}$ & Honshu & $\sim 37^{\circ} 08^{\prime} \mathrm{N}$ & $\sim 138^{\circ} 14^{\prime} \mathrm{E}$ & $\begin{array}{l}\text { Gardens and } \\
\text { mature }\end{array}$ & $<4$ & $<4$ & $<4$ & $\begin{array}{l}\text { Dominated by } 2 \text { tit species } \\
\text { and Aegithalos caudatus }\end{array}$ \\
\hline $\begin{array}{l}\text { Lee and Jabłoński }(1999,2006) ; \\
\text { Jabłoński and Lee }(2002)\end{array}$ & Seoul & $\sim 37^{\circ} 33^{\prime} \mathrm{N}$ & $\sim 126^{\circ} 58^{\prime} \mathrm{E}$ & Mature & 4 & $<8$ & $<8$ & $\begin{array}{l}\text { Dominated by } 4 \text { tit species } \\
\text { and Aegithalos caudatus }\end{array}$ \\
\hline Ogasawara $(1965,1970,1975)$ & Honshu & $\sim 38^{\circ} 15^{\prime} \mathrm{N}$ & $\sim 140^{\circ} 53^{\prime} \mathrm{E}$ & Gardens & $\mathrm{n} / \mathrm{a}$ & n/a & $\mathrm{n} / \mathrm{a}$ & $\begin{array}{l}\text { Dominated by } 4 \text { tit species } \\
\text { and Aegithalos caudatus }\end{array}$ \\
\hline Hino (2005) & Hokkaido & $\sim 43^{\circ} 10^{\prime} \mathrm{N}$ & $\sim 141^{\circ} 22^{\prime} \mathrm{E}$ & Mature & $\mathrm{n} / \mathrm{a}$ & n/a & $\mathrm{n} / \mathrm{a}$ & $\begin{array}{l}\text { Dominated by } 2 \text { tit species } \\
\text { and Aegithalos caudatus }\end{array}$ \\
\hline Gao (1987, 1991); Gao et al. (1993) & Jilin & $44^{\circ} 01^{\prime}-44^{\circ} 06^{\prime} \mathrm{N}$ & $126^{\circ} 00^{\prime}-126^{\circ} 09^{\prime} \mathrm{E}$ & Mature & 4 & 8 & 10 & $\begin{array}{l}\text { Dominated by } 3 \text { tit species } \\
\text { and Aegithalos caudatus }\end{array}$ \\
\hline
\end{tabular}

Korean or Japanese, and we therefore could have missed studies in these countries. As yet, most studies have been descriptive, and so here we focus on just a few aspects of flocks: seasonality, species richness, and leadership. Taxonomy follows Gill and Donsker (2014).

As one might expect, there is a large difference between northern temperate flocks and tropical ones in seasonality. Ogasawara (1965) described in detail the seasonality of a temperate Japanese flock system, starting from June for some species after breeding, peaking in the early autumn and disbanding again in March. Such systems are also encountered in Korea (Lee and Jabłoński 1999) and northern China (Gao 1987); and contrast strongly with Chinese tropical flock systems such as those in Hainan, which do not have any noticeable differences between seasons (Zou et al. 2011). The seasonal variation in flocking in between these two extremes requires greater study. For example, in Guangdong, seasonal differences were low, although there is a noticeable decrease in flock size in April, May and June (Zhang et al. 2013), perhaps associated with the breeding season.

Species richness is also correlated with latitude. For example, in northern China and Korea, an average (from four studies; see Table 1) of 4 species were found in $25 \%$ of flocks, and 6.5 species in $5 \%$ of flocks. In comparison, in mature forest of South China, an average (from four studies; see Table 1) of 6 species were in 25\% of flocks, and an average of 19.8 in 5\%. However, presently we are unable to distinguish whether southern flocks are larger simply because there are more species in these areas, or because the flocks are a larger percentage of the avifauna, as only two studies in the region (Zou et al. 2011; Zhang et al. 2013) have data on birds both inside and outside of flocks.

Compositional studies also show large differences between southern and northern China, especially in which species play nuclear roles for flocks. The fulvetta species Alcippe davidi, A. hueti and A. morrisonia are the nuclear species in forested habitats in southern China (see Table 1), and have been reported to lead flocks as far west as Yunnan (Wang 1983; where the species would likely be $A$. fratercula). These species are extremely gregarious, with between 21.2 and 32.5 individuals per flock. Alcippe species play important roles in flocks outside of East Asia, too: A poioicephala plays a leading role in flocks in Malaysia and India (McClure 1967; Sridhar et al. 2013). Other members of the families Timaliidae, Pellorneidae, Leiothrichidae (Fregin et al. 2012; groups traditionally called "babblers") are also frequently noted to be mixed-species flock participants in books on the Chinese avifauna, and especially in southern China (Zhuge 1990; MacKinnon and Phillipps 2000; Zhao 2001).

In contrast, the flocks of the northern part of the region are dominated by the tit (Paridae) and bushtit (Aegithalidae) families. The species Parus major, Periparus ater, Poecilepalustris, Sittiparus varius and Aegithalos caudatus are all found in multiple flock systems, often together, and Regulus regulus (Regulidae) is another common participant (Song 
1981; Gao 1987; Gao et al. 1993; Lee and Jabłoński 1999; Hino 2005). In addition, Poecile montanus has been described in flocks (Ogasawara 1965), and is potentially important in flock formation (Suzuki 2012). Among these different species, there is little information as to which species lead the flock, although Seki and Sato (2002) observed Aegithalos caudatus to be a leader when present. Following these species are a variety of nuthatches, creepers and woodpeckers.

Beyond these two clear flocking types, there may be other flock types, especially in areas of intermediate latitude or in early successional habitat. For example, on the tops of mountains in southeast China, A. hueti may be rare and other species, such as the Red-billed Leothrix Leothrix lutea, can lead flocks (A. Jiang, J. Zhao and Q. Zhang, personal communication). In Zhejiang Province, Aegithalos concinnus and Pardaliparus venustulus are described as flocking species (Zhuge 1990); another southern tit flock participant may be Machlolophus spilonotus (Zhao 2001). White-eyes (Zosteropidae) often form multispecies flocks in disturbed habitat (Kawakami and Higuchi 2003) and can serve as leaders of flocks with low cohesion in human-dominated ecosystems (Zhang et al. 2013; Mammides et al., unpublished manuscript on birds of South Asia; E. Goodale, personal observation in Xishuangbanna, Yunnan Province). Phylloscopus warblers may form multispecies flocks, especially close to migration time (Gao 1987), and members of the Seicercus genus have also been observed in flocks (Zhuge 1990).

A few generalizations can be made regarding the literature from this region. East Asian flocks are notable for the high numbers of individuals per flock, due to the presence of gregarious leading species, a characteristic also noted in South Asia (Goodale et al. 2009), and contrasting to tropical America, where most species have just a few individuals (Powell 1985). The gregarious nuclear species in these groups may consist of stable flocks of mated pairs such as parids (Smith 1991), or perhaps closely related family groups (although it should be noted that fulvettas do not appear to be cooperative breeders; Collar et al. 2013), and hence participate in seemingly altruistic behavior that benefit their kin or mates (Maynard Smith 1965). Sentinel species, represented by the drongos, are also present in some tropical and subtropical flocks (Chen and Hsieh 2002; Jiang 2007; Zou et al. 2011). Other fly-catching species could also serve as sentinels, as does the Grey-headed Canary Flycatcher (Culicicapa ceylonensis) in flocks of disturbed habitats in Xishuangbanna, Yunnan (E. Goodale, personal observation).

\section{The future of studies of flocks in East Asia} A need for more flock observations and research in East Asia While there is a strong foundation for flock studies in the region, there are some clear knowledge gaps that need to be filled including the composition and structure of flocks at intermediate latitudes, particularly in central and western China, and in human-disturbed environments, as the pioneering Zhang et al. (2013) article is the only study yet to concentrate on how flocks in early successional forest compare to those in mature forest. It would be particularly interesting to see whether birds in any area have the choice of joining tit-led flocks as opposed to babbler-led flocks, or even joining another system like that of white-eyes or warblers.

Flock observations need not only be reserved for professional ornithologists because there is a new group of skilled bird-watchers in the region from whom it may be possible to gather information ( $\mathrm{Si}$ and Ding 2011; Ma et al. 2013). Efforts are currently underway to have data compilers, such as eBird (ebird.org) or the Chinesefocused site, Chinese Bird Report (birdtalker.net), incorporate mixed-species flock data into their data collection protocols.

As East Asia has a great range of latitudes, elevations and natural ecosystems, and because anthropogenic stress on natural ecosystems is high, leading to many kinds of human-modified and human-dominated habitats, we also see a range of fruitful ways in which scientists in this region can investigate flocks. Based on our review of flock structure and response to human disturbance, there are some critical questions as yet unanswered: what enhances flock persistence in disturbed environments, how much space do flocks require and how dependent are species on each other in flocks? Here we discuss these questions in turn, also suggesting some observational and experimental approaches that can address them.

\section{Studies of flock persistence in human-modified habitats}

The question of whether flocking species are especially vulnerable to anthropogenic change still needs to be answered for a variety of regions and environments. Further, it is critical to know how important flocks are to the persistence of birds in a fragmented landscape. Studies of foraging ecology (measuring foraging rates, efficiency and head scans) would be useful over a gradient of human disturbance (Tellería et al. 2001; Pomara et al. 2003). Even better would be the ability to look at direct measures of birds' fitness, such as nest success in disturbed areas with and without flocks (although finding comparable areas is always difficult; see experimental approaches below).

Work on what habitat features enable flocks to persist in human-modified areas would also be a productive research direction. What vegetational characteristics are needed? Can flocks move through areas using "corridors" or "stepping stone" patches of forest habitat? An experimental paradigm involving translocation of birds 
away from their territory and observations of what habitat they use on their way back (e.g., Gillies and St Clair 2010) might also be useful to use on nuclear species, although one might have to translocate groups of such species, since they are usually not naturally alone.

\section{Studies of the use of space by flocks}

In order to determine how flocks can be conserved in human-modified areas, we need to better understand their movement patterns and how much space they require. As noted above, there is a clear lack of studies of color-banded flocks outside Central/South America and Australia. Such studies are really the only way to understand how individual birds are using space in flocks and outside of them, and are required both in natural habitats in Asia as well as in fragmented landscapes.

\section{Flock interdependency: studies along gradients}

How co-evolved are flock systems, and how dependent are species on specific heterospecifics in flocks? One approach to this question is to study an environmental or disturbance gradient and see if the ranges of species with high propensity to flock begin and end randomly or coincide. Such studies have been used to investigate competition (e.g., Terborgh 1971; Jankowski et al. 2012). In the flocking context, if species that participate in flocks are all clumped together on such a gradient, it would provide evidence for the flock or a particularly important leader affecting the distribution of species along the gradient (Fig. 2). This gradient could be elevation, or fragmentation, or land-use intensification. For example, the Thousand Island Lake system in eastern China (Wang et al. 2011) could be an excellent system in which to look for fragmentation effects. The flock leading species Alcippe hueti is found on 35 of these 42 islands (Wang et al. 2011), so it would be interesting to see what

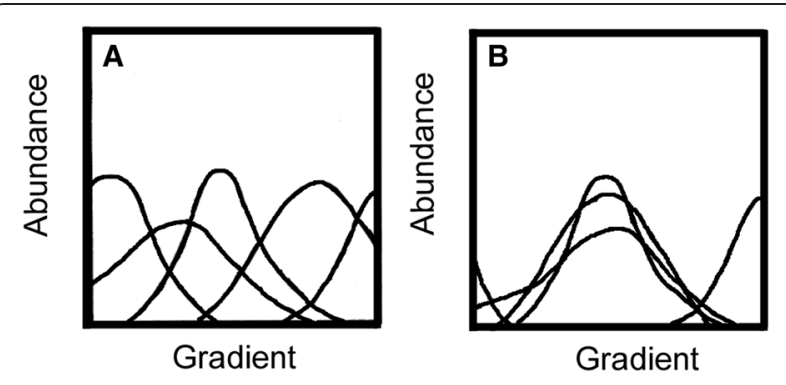

Fig. 2 A hypothetical example of abundances of several bird species across a gradient, when (a) their distributions are independent of each other and (b) their distributions coincide. In (b) if the species that coincide are all flocking species, it suggests an effect of the flock system or a flock leader. However, mechanistic studies are required to demonstrate that the species interact and that this is not simply the result of habitat filtering. Figure modified from Terborgh (1971) happens to flocks and the pool of bird species on the remaining seven islands.

As intuitive as this approach sounds, clumping of species in one area could also be evidence of habitat filtering, that is, birds with similar phenotypes responding to habitats in similar ways (Jankowski et al. 2012). Hence, this approach is best used in conjunction with mechanistic or experimental approaches (see below). Another way to investigate whether habitat filtering is responsible for community structure is a phylogenetic analysis, for if habitat filtering is occurring in an area, species are expected to be more phylogenetically similar than expected by chance (Webb et al. 2002), assuming that phylogenetically related species are more phenotypically similar. A recent study (Gómez et al. 2010) has taken such a phylogenetic approach, combined with models of trait evolution, to analyze antbird assemblages in mixed-species flocks in Amazonia and found evidence for phylogenetic clumping. Perhaps this clumping is due to relaxed competition, as expected in mutualisms (Sridhar et al. 2012). The result warrants replication, and further conceptual work should investigate whether facilitation has the same or different implications for these analyses as reduced competition.

\section{Flock interdependency: experimental studies}

Experimental studies remain the most powerful way to determine how flocking effects fitness. For example, Grubb and colleagues were able to remove species from flocks that are found in small pockets of forest in an agricultural landscape, and then measure the effects on the body condition of the remaining birds (Cimprich and Grubb 1994; Dolby and Grubb 1998, 1999). One can imagine potential experiments on the Thousand Island Lake landscape (Wang et al. 2011), discussed above, where fulvettas could be removed from islands, or even added to islands where they were not before, with the one complicating problem that the resulting flocks would not only be different in the presence of this one species, but also in the number of individuals per flock (due to the species being highly gregarious).

As removal experiments are difficult to accomplish, however, playback can be used as another technique to measure interspecific relationships. For example, after observations of elevational gradients suggested interspecific interactions, playback trials were used to demonstrate interspecific aggression (Jankowski et al. 2010). In an analogous manner, several studies have used the playback of a species' vocalizations to simulate that species' presence and then measured approaches by heterospecifics to determine the importance of that species to the community (Mönkkönen et al. 1996), or specifically to other flocking species (Goodale and Kotagama 2005b; Goodale et al. 2012; Cordeiro et al. 2014). While these 
kinds of experiments have their limitations (e.g., impossible or difficult to simulate non-vocal species or those with low-amplitude vocalizations, inability to measure exploitation competition), they can be used in conjunction with observations to understand the community structure of flocks.

\section{Conclusions}

In the introduction, we summarized two different approaches to studying the community ecology of mixedspecies flocks: 1) how are these subsamples of an avian community organized in terms of which species are included and which species play important roles, and 2) how does the flock phenomenon influence the structure of the overall community? Research on mixed-species flocks has so far focused on the more manageable first approach. Yet the set of questions involved in the second approach are, we believe, particularly important to understanding the implications of flocking for conservation. While the current research suggests that flocks are negatively affected by human disturbance, we still do not understand what happens to birds when flocks disappear or how can we enhance their persistence. The ecological breadth of the region, the vast amount of humanmodified habitats, and the increase of skilled observers and potential students of flocking, afford tremendous opportunities for East Asia in the century to come.

\section{Competing interests}

The authors declare that they have no competing interests.

\section{Authors' contributions}

All authors contributed to developing the ideas and writing the manuscript. All authors have read and approved the final version of the manuscript.

\section{Acknowledgements \\ We thank Aiwu Jiang, Yang Liu, Toshitaki Suzuki, Qiang Zhang, Chao Zhao, Jian Zhao and Fasheng Zou for discussion of East Asian mixed-species flocks and their help in obtaining the literature, and two anonymous reviewers on their constructive comments for improving the manuscript. EG is grateful to the 1000 Plan Recruitment Program of Global Experts of the People's Republic of China and the Special Talent Recruitment Program of Guangx University for support. \\ Author details \\ 1Department of Forestry, Guangxi University, Nanning 530003, China. ${ }^{2}$ College of Life Sciences, Zhejiang University, Hangzhou 310058, China. ${ }^{3}$ Wildlife Conservation Society, China Program, Beijing 100101, China. ${ }^{4}$ Department of Biology, San Francisco State University, San Francisco, CA 94132, USA. ${ }^{5}$ Department of Biology, University of Florida, Gainesville, FL 32607, USA. ${ }^{6}$ Florida Museum of Natural History, University of Florida, Gainesville, FL 32611, USA.}

Received: 15 August 2014 Accepted: 2 June 2015

Published online: 01 August 2015

\section{References}

Alatalo RV (1981) Interspecific competition in tits Parus spp. and the Goldcrest Regulus regulus: foraging shifts in multispecific flocks. Oikos 37:335-44 Alatalo RV, Gustafsson L, Linden M, Lundberg A (1985) Interspecific competition and niche shifts in tits and the goldcrest: an experiment. J Anim Ecol 54:977-84
Alatalo RV, Eriksson DAG, Gustafsson L, Larsson K (1987) Exploitation competition influences the use of foraging sites by tits: experimental evidence. Ecology 68:284-90

Aplin LM, Farine DR, Morand-Ferron J, Sheldon BC (2012) Social networks predict patch discovery in a wild population of songbirds. Proc $R$ Soc Lond B 279:4199-205

Buskirk WH (1976) Social systems in a tropical forest avifauna. Am Nat 110:293-310

Buskirk WH, Powell GVN, Wittenberger JF, Buskirk RE, Powell TU (1972) Interspecific bird flocks in tropical highland Panama. Auk 89:612-24

Caraco T, Martindale S, Pulliam HR (1980) Avian flocking in the presence of a predator. Nature 285:400-1

Chen C-C, Hsieh H (2002) Composition and foraging behaviour of mixed-species flocks led by the grey-cheeked fulvetta in fushan experimental forest, Taiwan. Ibis 144:317-30

Cimprich DA, Grubb TC Jr (1994) Consequences for Carolina chickadees of foraging with Tufted Titmice in winter. Ecology 75:1615-25

Collar N, Robson C, Christie DA (2013) Grey-cheeked Fulvetta (Alcippe morrisonia). In: del Hoyo J, Elliott A, Sargatal J, Christie DA, de Juana E (eds) Handbook of the Birds of the World Alive. Lynx Edicions, Barcelona

Colorado GJ (2013) Why animals come together, with the special case of mixedspecies bird flocks. Rev Esc Ingeniería de Antioquia 10:49-66

Colorado GJ, Rodewald AD (2015) Assembly patterns of mixed-species avian flocks in the Andes. J Anim Ecol 84:386-95

Colorado GJ, Rodewald AD (in press) Response of mixed-species flocks to habitat alteration and deforestation in the Andes. Biol Conserv. doi:10.1016/ j.biocon.2015.02.008

Contreras TA, Sieving KE (2011) Leadership of winter mixed-species flocks by Tufted Titmice (Baeolophus bicolor): are titmice passive nuclear species? Int J Zool 2011:670548

Cordeiro NJ, Borghesio L, Joho M, Monoski T, Mkongewa V (2014) Forest fragmentation in an African biodiversity hotspot impacts mixed species foraging bird flocks. Biol Conserv. doi:10.1016/j.biocon.2014.09.050

Darrah AJ, Smith KG (2013) Comparison of foraging behaviors and movement patterns of the Wedge-billed Woodcreeper (Glyphorynchus spirurus) traveling alone and in mixed-species flocks in Amazonian Ecuador. Auk 130:629-36

Develey PF, Stouffer PC (2001) Effects of roads on movements by understorey birds in mixed-species flocks in central Amazonian Brazil. Conserv Biol $15: 1416-22$

Diamond JM (1981) Mixed-species foraging groups. Nature 292:408-9

Dolby AS, Grubb TC Jr (1998) Benefits to satellite members in mixed-species foraging groups: an experimental analysis. Anim Behav 56:501-9

Dolby AS, Grubb TC Jr (1999) Functional roles in mixed-species foraging flocks: a field manipulation. Auk 116:557-9

Dolby AS, Grubb TC Jr (2000) Social context affects risk taking by a satellite species in a mixed-species foraging group. Behav Ecol 11:110-4

Eguchi K, Yamagishi S, Randrianasolo V (1993) The composition and foraging behaviour of mixed-species flocks of forest-living birds in Madagascar. Ibis 135:91-6

Farine DR, Milburn PJ (2013) Social organisation of thornbill-dominated mixedspecies flocks using social network analysis. Behav Ecol Sociobiol 67:321-30

Fernández-Juricic E (2000) Forest fragmentation affects winter flock formation of an insectivorous guild. Ardea 88:235-41

Fernández-Juricic E (2002) Nested patterns of species distribution and winter flock occurrence of insectivorous birds in a fragmented landscape. Ecoscience 9:450-8

Fregin S, Haase M, Olsson U, Alström P (2012) New insights into family relationships within the avian superfamily Sylvioidea (Passeriformes) based on seven molecular markers. BMC Evol Biol 12:157

Galef BG, Giraldeau L-A (2001) Social influences on foraging in vertebrates: causal mechanisms and adaptive functions. Anim Behav 61:3-15

Gao W (1987) Study of flocks of terrestrial birds on Mt. Changbai and their annual activities. J Northeast Normal Univ 1987:63-72

Gao W (1991) The relationship of birds in mixed flocks in winter in a planted larch forest. Chinese J Zool 26:9-12

Gao W, Feng H-L, Xiang G-Q, Yang Z-J, Cheng H (1993) On bird flocking in secondary forest of mountainous district in winter. Acta Zool Sinica 39:385-91

Gill F, Donsker D (2014) International Ornithologists' Union world bird list (v. 3.3). http://www.worldbirdnames.org/

Gillies CS, St Clair CC (2010) Functional responses in habitat selection by tropical birds moving through fragmented forest. J Appl Ecol 47:182-90

Gómez JP, Bravo GA, Brumfield RT, Tello JG, Cadena CD (2010) A phylogenetic approach to disentangling the role of competition and habitat filtering in community assembly of Neotropical forest birds. J Anim Ecol 79:1181-92 
Goodale E, Beauchamp G (2010) The relationship between leadership and gregariousness in mixed-species bird flocks. J Avian Biol 41:99-103

Goodale E, Kotagama SW (2005a) Alarm calling in Sri Lankan mixed-species bird flocks. Auk 122:108-20

Goodale E, Kotagama SW (2005b) Testing the roles of species in mixed-species bird flocks of a Sri Lankan rainforest. J Trop Ecol 21:669-76

Goodale E, Nizam BZ, Robin W, Sridhar H, Trivedi P, Kotagama SW, Padmalal UKGK, Perera R, Pramod P, Vijayan L (2009) Regional variation in the composition and structure of mixed-species bird flocks in the Western Ghats and Sri Lanka. Curr Sci India 97:648-63

Goodale E, Beauchamp G, Magrath R, Nieh JC, Ruxton GD (2010) Interspecific information transfer influences animal community structure. Trends Ecol Evol 25:354-61

Goodale E, Goodale UM, Mana R (2012) The role of toxic pitohuis in mixedspecies flocks of lowland forest in Papua New Guinea. Emu 112:9-16

Goodale E, Kotagama SW, Raman TRS, Sidhu S, Goodale UM, Parker S, Chen J (2014) The response of birds and mixed-species bird flocks to human-modified landscapes in Sri Lanka and southern India. Forest Ecol Manag 329:384-92

Gradwohl J, Greenberg R (1980) The formation of antwren flocks on Barro Colorado Island, Panama. Auk 97:385-95

Gram WK (1998) Winter participation by Neotropical migrant and resident birds in mixed-species flocks in northeastern Mexico. Condor 100:44-53

Graves GR, Gotelli NJ (1993) Assembly of avian mixed-species flocks in Amazonia. Proc Natl Acad Sci U S A 90:1388-91

Greenberg R (2000) Birds of many feathers: the formation and structure of mixed-species flocks of forest birds. In: Boinski S, Garber PA (eds) On the move: how and why animals travel in groups. University of Chicago Press, Chicago, pp 521-58

Greig-Smith PW (1981) The role of alarm responses in the formation of mixed species flocks of heathland birds. Behav Ecol Sociobiol 8:7-10

Harrison NM, Whitehouse MJ (2011) Mixed-species flocks: an example of niche construction? Anim Behav 81:675-82

Hino T (1998) Mutualistic and commensal organization of avian mixed-species foraging flocks in a forest of western Madagascar. J Avian Biol 29:17-24

Hino T (2005) Resident males of small species dominate immigrants of large species in heterospecific, winter bird flocks. Ornithol Sci 4:89-94

Holt RD (1997) Community modules. In: Gange AC, Brown VK (eds) Multitrophic interactions in terrestrial ecosystems. Blackwell Science, Oxford, pp 333-49

Hsieh H, Chen C-C (2011) Does niche-overlap facilitate mixed-species flocking in birds? J Ornithol 152:955-63

Hutto RL (1987) A description of mixed-species insectivorous bird flocks in western Mexico. Condor 89:282-92

Hutto RL (1988) Foraging behaviour patterns suggest a possible cost associated with participation in mixed-species bird flocks. Oikos 51:79-83

Jabłoński PG, Lee SD (2002) Foraging niche shifts in mixed-species flocks of tits in Korea. J Field Ornithol 73:246-52

Jankowski JE, Robinson SK, Levey DJ (2010) Squeezed at the top: interspecific aggression may constrain elevational ranges in tropical birds. Ecology 91:1877-84

Jankowski JE, Graham CH, Parra JL, Robinson SK, Seddon N, Touchton JM, Tobias JA (2012) The role of competition in structuring tropical bird communities. Ornitol Neotrop 23:115-24

Jiang A (2007) The study of understory birds in Nonggang karst forest. MSc Thesis, Guangxi University, Nanning

Jullien M, Clobert J (2000) The survival value of flocking in neotropical birds: reality or fiction? Ecology 81:3416-30

Jullien M, Thiollay J-M (1998) Multi-species territoriality and dynamic of neotropical forest understorey bird flocks. J Anim Ecol 67:227-52

Kawakami K, Higuchi H (2003) Interspecific interactions between the native and introduced White-eyes in the Bonin Islands. Ibis 145:583-92

Kiers ET, Palmer TM, Ives AR, Bruno JF, Bronstein JL (2010) Mutualisms in a changing world: an evolutionary perspective. Ecol Lett 13:1459-74

King DI, Rappole JH (2000) Winter flocking of insectivorous birds in montane pine-oak forests in middle America. Condor 102:664-72

Knowlton JL, Graham CH (2011) Species interactions are disrupted by habitat degradation in the highly threatened Tumbesian region of Ecuador. Ecol Appl 21:2974-86

Kotagama SW, Goodale E (2004) The composition and spatial organization of mixed-species flocks in a Sri Lankan rainforest. Forktail 20:63-70

Krams I (2001) Seeing without being seen: a removal experiment with mixed flocks of willow and crested tits Parus montanus and cristatus. Ibis 143:476-81
Krebs JR (1973) Social learning and the significance of mixed-species flocks of chickadees (Parus spp.). Can J Zool 51:1275-88

Kubota H, Nakamura M (2000) Effects of supplemental food on intra-and inter-specific behaviour of the Varied Tit Parus varius. Ibis 142:312-9

Latta SC, Wunderle JM (1996) The composition and foraging ecology of mixedspecies flocks in pine forests of Hispaniola. Condor 98:595-607

Lee SD, Jabłoński PG (1999) Species composition and use of coniferous and deciduous trees in mixed-species flocks wintering near Seoul (Korea). Act Ornithol 34:81-4

Lee SD, Jabłoński PG (2006) Spatial segregation of foraging sites in winter mixedspecies flocks of forest birds near Seoul, Korea. Pol J Ecol 54:481-90

Lee TM, Soh MCK, Sodhi N, Koh LP, Lim SL-H (2005) Effects of habitat disturbance on mixed species bird flocks in a tropical sub-montane rainforest. Biol Conserv 122:193-204

Ma Z, Cheng Y, Wang J, Fu X (2013) The rapid development of birdwatching in mainland China: a new force for bird study and conservation. Bird Conserv Int 23:259-69

MacKinnon J, Phillipps K (2000) A field guide to the birds of China. Oxford University Press, Oxford, UK

Maldonado-Coelho M, Marini MA (2000) Effects of forest fragment size and successional stage on mixed-species bird flocks in southeastern Brazil. Condor 102:585-94

Maldonado-Coelho M, Marini MA (2004) Mixed-species bird flocks from Brazilian Atlantic forest: the effects of forest fragmentation and seasonality on their size, richness and stability. Biol Conserv 116:19-26

Martínez AE, Gomez JP (2013) Are mixed-species bird flocks stable through two decades? Am Nat 181:E53-9

Maynard Smith J (1965) The evolution of alarm calls. Am Nat 99:59-63

McClure HE (1967) The composition of mixed-species flocks in lowland and sub-montane forests of Malaya. Wilson Bull 79:131-54

McDermott ME, Rodewald AD (2014) Conservation value of silvopastures to Neotropical migrants in Andean forest flocks. Biol Conserv 175:140-7

Mokross K, Ryder TB, Côrtes MC, Wolfe JD, Stouffer PC (2014) Decay of interspecific avian flock networks along a disturbance gradient in Amazonia. Proc R Soc Lond B 281:20132599

Mönkkönen M, Forsman JT, Helle P (1996) Mixed-species foraging aggregations and heterospecific attraction in boreal bird communities. Oikos 77:127-36

Morse DH (1970) Ecological aspects of some mixed-species foraging flocks of birds. Ecol Monogr 40:119-68

Morse DH (1977) Feeding behavior and predator avoidance in heterospecific groups. Bioscience 27:332-9

Moynihan M (1962) The organization and probable evolution of some mixedspecies flocks of Neotropical birds. Smithson Misc Coll 143:1-140

Munn CA (1984) The behavioral ecology of mixed-species bird flocks in Amazonian Peru. Princeton University, New Jersey

Munn CA (1985) Permanent canopy and understorey flocks in Amazonia: species composition and population density. Ornithol Monogr 36:683-712

Munn CA, Terborgh JW (1979) Multi-species territoriality in Neotropical foraging flocks. Condor 81:338-47

Nakamura M, Shindo N (2001) Effects of snow cover on the social and foraging behavior of the great tit Parus major. Ecol Res 16:301-8

Ogasawara K (1965) The analysis of the mixed flock of the family Paridae in the botanical garden of the Tôhuku University, Sendai. I: Seasonal change of the flock formation. Scientific Report of the Tôhuku University. Series IV (Biology) 31:167-80

Ogasawara K (1970) Analysis of mixed-species flocks of tits in the botanical garden of Tôhoku University Sendai II Foragin g layers by species and their interrelations within the mixed flock. Miscellaneous Reports of the Yamashima Institute of Ornithology 6:170-8

Ogasawara K (1975) Analysis of mixed-species flocks of tits in the botanical garden of Tôhoku University, Sendai. IV. Foraging habits and supplanting attacks among species forming mixed flocks. Miscellaneous Reports of the Yamashima Institute of Ornithology 12:637-51

Péron G, Crochet P-A (2009) Edge effect and structure of mixed-species bird flocks in an Afrotropical lowland forest. J Ornithol 150:585-99

Pierpont N (1986) Interspecific aggression and the ecology of woodcreepers (Aves: Dendrocolaptidae). Princeton University, Princeton, New Jersey, PhD Thesis

Pomara LY, Cooper RJ, Petit LJ (2003) Mixed-species flocking and foraging behavior of four neotropical warblers in Panamanian shade coffee fields and forests. Auk 120:1000-12

Pomara LY, Cooper RJ, Petit LJ (2007) Modeling the flocking propensity of passerine birds in two Neotropical habitats. Oecologia 153:121-33 
Powell GVN (1985) Sociobiology and adaptive significance of interspecific foraging flocks in the Neotropics. Ornithol Monogr 36:713-32

Satischandra SHK, Kudavidanage EP, Kotagama SW, Goodale E (2007) The benefits of joining mixed-species flocks for a sentinel nuclear species, the Greater Racket-tailed Drongo Dicrurus paradiseus. Forktail 23:145-8

Seki S-I, Sato T (2002) The effect of a typhoon on the flocking and forgaging behavior of tits. Ornithol Sci 1:53-61

Si X-F, Ding P (2011) History, status of monitoring landbirds in Europe and America and countermeasures of China. Biodiv Sci 19:303-10

Sidhu S, Raman TRS, Goodale E (2010) Effects of plantations and home-gardens on tropical forest bird communities and mixed-species bird flocks in the southern Western Ghats. J Bombay Nat Hist Soc 107:91-108

Sieving KE, Contreras TA, Maute KL (2004) Heterospecific facilitation of forest boundary crossing by mobbing understory birds in north-central Florida. Auk 121:738-51

Smith SM (1991) The Black-capped Chickadee: behavioral ecology and natural history. Comstock Books, Ithaca

Song Y-J (1981) Studies on the breeding behaviour and feeding habits of Long-tailed tit. Zool Res 2:235-42

Sridhar H, Sankar K (2008) Effects of habitat degradation on mixed-species bird flocks in Indian rain forests. J Trop Ecol 24:135-47

Sridhar H, Shanker K (2014) Using intra-flock association patterns to understand why birds participate in mixed-species foraging flocks in terrestrial habitats. Behav Ecol Sociobiol 68:185-96

Sridhar H, Beauchamp G, Shanker K (2009) Why do birds participate in mixed-species foraging flocks? A large-scale synthesis. Anim Behav 78:337-47

Sridhar H, Srinivasan U, Askins RA, Canales-Delgadillo JC, Chen C-C, Ewert DN, Gale GA, Goodale E, Gram WK, Hart PJ, Hobson KA, Hutto RL, Kotagama SW Knowlton JL, Lee TM, Munn CA, Nimnuan S, Nizam BZ, Péron G, Robin W, Rodewald AD, Rodewald PG, Thomson RL, Trivedi P, Van Wilgenburg SL, Shanker K (2012) Positive relationships between association strength and phenotypic similarity characterize the assembly of mixed-species bird flocks worldwide. Am Nat 180:777-90

Sridhar H, Jordán F, Shanker K (2013) Species importance in a heterospecific foraging association network. Oikos 122:1325-34

Srinivasan U, Quader S (2012) To eat and not be eaten: modelling resources and safety in multi-species animal groups. PLoS One 7, e42071

Srinivasan U, Raza RH, Quader S (2010) The nuclear question: rethinking species importance in multi-species animal groups. J Anim Ecol 79:948-54

Stouffer PC, Bierregaard RO Jr (1995) Use of Amazonian forest fragments by understory insectivorous birds. Ecology 76:2429-45

Sullivan KA (1984) Information exploitation by downy woodpeckers in mixedspecies flocks. Behaviour 91:294-311

Suzuki TN (2012) Long-distance caling by the Willow Tit, Poecile montanus, facilitates formation of mixed-species foraging flocks. Ethology 118:10-6

Tellería JL, Virgós E, Carbonell R, Pérez-Tris J, Santos T (2001) Behavioural responses to changing landscapes: flock structure and anti-predator strategies of tits wintering in fragmented forests. Oikos 95:253-64

Terborgh J (1971) Distribution on environmental gradients: theory and preliminary investigation of distributional patterns in the avifauna of the Cordillera Vilcabamba, Peru. Ecology 52:23-40

Terborgh J (1990) Mixed flocks and polyspecific associations: costs and benefits of mixed groups to birds and monkeys. Am J Primatol 21:87-100

Terborgh J, Lopez L, Nuñez P, Rao M, Shahabuddin G, Orihuela G, Riveros M, Ascanio R, Adler GH, Lambert TD, Balbas L (2001) Ecological meltdown in predator-free forest fragments. Science 294:1923-6

Thiollay J-M (1992) Influence of selective logging on bird species diversity in a Guianan rain forest. Conserv Biol 6:47-60

Thiollay J-M (1999a) Frequency of mixed-species flocking in tropical forest birds and correlates of predation risk: an intertropical comparison. J Avian Biol 30:282-94

Thiollay J-M (1999b) Responses of an avian community to rain forest degradation. Biodiv Conserv 8:513-34

Thiollay J-M (2003) Comparative foraging behavior between solitary and flocking insectivores in a Neotropical forest: does vulnerability matter? Ornitol Neotrop 14:47-65

Thiollay J-M, Jullien M (1998) Flocking behaviour of foraging birds in a neotropical rain forest and the antipredator defence hypothesis. Ibis 140:382-94

Tubelis DP, Cowling A, Donnelley C (2006) Role of mixed-species flocks in the use of adjacent savannas by forest birds in the central Cerrado, Brazil. Austral Ecol 31:38-45
Tylianakis JM, Laliberté E, Nielsen A, Bascompte J (2009) Conservation of species interaction networks. Biol Conserv 143:2270-9

Valburg LK (1992) Flocking and frugivory: the effect of social groupings on resource use in the Common Bush-Tanager. Condor 94:358-63

Valiente-Banuet A, Aizen MA, Alcántara JM, Arroyo J, Cocucci A, Galetti M, García MB, García D, Gómez JM, Jordano P (2015) Beyond species loss: the extinction of ecological interactions in a changing world. Funct Ecol 29:299-307

Van Houtan KS, Pimm SL, Bierregaard RO Jr, Lovejoy TE, Stouffer PC (2006) Local extinctions in flocking birds in Amazonian forest fragments. Evol Ecol Res 8:129-48

Waite TA, Grubb TC Jr (1988) Copying of foraging locations in mixed-species flocks of temperate-deciduous woodland birds: an experimental study. Condor 90:132-40

Wang Z (1983) Some information on birds of the bamboo jungle in the Xujiaba evergreen broadleaf forest. Act Ecol Sinica 3:393-8

Wang Y, Chen S, Ping D (2011) Testing mutliple assembly rule models in avian communities on islands of an inundated lake, Zhejiang Province, China. J Biogeogr 38:1330-44

Webb CO, Ackerly DD, McPeek MA, Donoghue MJ (2002) Phylogenies and community ecology. Annu Rev Ecol Syst 33:475-505

Winterbottom JM (1943) On woodland bird parties in Northern Rhodesia. Ibis 85:437-42

Zhang Q, Han RC, Zhang M, Huang Z, Zou F (2013) Linking vegetation structure and bird organization: response of mixed-species bird flocks to forest succession in subtropical China. Biodiv Conserv 22:1965-89

Zhao Z (2001) The birds of China. Jilin Science and Technology Press, Changchun, Jilin

Zhuge Y (1990) Fauna of Zhejiang: Aves. Zhejiang Science and Technology Publishing House, Hangzhou

Zou F, Chen G, Yang Q, Fellowes J (2011) Composition of mixed-species flocks and shifts in foraging location of flocking species on Hainan Island, China. |bis 153:269-78

\section{Submit your next manuscript to BioMed Central and take full advantage of:}

- Convenient online submission

- Thorough peer review

- No space constraints or color figure charges

- Immediate publication on acceptance

- Inclusion in PubMed, CAS, Scopus and Google Scholar

- Research which is freely available for redistribution 